\title{
Neurogenin 3 is essential for the proper specification of gastric enteroendocrine cells and the maintenance of gastric epithelial cell identity
}

\author{
Catherine S. Lee, ${ }^{1}$ Nathalie Perreault, ${ }^{1}$ John E. Brestelli, and Klaus H. Kaestner ${ }^{2}$ \\ Department of Genetics, University of Pennsylvania School of Medicine, Philadelphia, Pennsylvania 19104, USA
}

\begin{abstract}
The notch signaling pathway is essential for the endocrine cell fate in various tissues including the enteroendocrine system of the gastrointestinal tract. Enteroendocrine cells are one of the four major cell types found in the gastric epithelium of the glandular stomach. To understand the molecular basis of enteroendocrine cell development, we have used gene targeting in mouse embryonic stem cells to derive an EGFP-marked null allele of the bHLH transcription factor, neurogenin 3 (ngn3). In ngn ${ }^{-/-}$mice, glucagon secreting A-cells, somatostatin secreting D-cells, and gastrin secreting G-cells are absent from the epithelium of the glandular stomach, whereas the number of serotonin-expressing enterochromaffin (EC) cells is decreased dramatically. In addition, ngn $3^{-/-}$mice display intestinal metaplasia of the gastric epithelium. Thus, ngn3 is required for the differentiation of enteroendocrine cells in the stomach and the maintenance of gastric epithelial cell identity.
\end{abstract}

[Key Words: Basic-helix-loop-helix (bHLH) protein; neurogenin 3 (ngn3); notch signaling; metaplasia; enteroendocrine cells; iFABP; Muc 2]

Received February 15, 2002; revised version accepted May 2, 2002.

The mouse stomach is divided into two domains, the proximal third, which is known as the forestomach and is lined with a keratinized squamous epithelium, and the distal two-thirds that make up the stomach proper, which is lined with a glandular epithelium containing four major cell types, that is, pit, parietal, zymogenic, and enteroendocrine cells (Lorenz and Gordon 1993; Gordon and Hermiston 1994). Endocrine cells produce peptide hormones that regulate various physiological functions (Skipper and Lewis 2000). The specification of endocrine cells from a population of precursor cells is thought to be in part mediated by the Notch-signaling pathway (Artavanis-Tsakonas et al. 1999). Upon activation by ligands such as Delta or Jagged on adjacent cells, the intracellular domain of the Notch receptor is cleaved and translocated to the nucleus with subsequent upregulation of downstream targets including the Hairy/ Enhancer of Split (HES) genes. The HES proteins then inhibit the expression of several bHLH transcription fac-

\footnotetext{
${ }^{1}$ These authors contributed equally to this work.

${ }^{2}$ Corresponding author.

E-MAIL kaestner@mail.med.upenn.edu; FAX (215) 573-5892.

Article and publication are at http://www.genesdev.org/cgi/doi/10.1101/ gad.985002.
}

tors including the neurogenin genes (Sommer et al. 1996; Artavanis-Tsakonas et al. 1999).

The bHLH transcription factors are instrumental in the determination of various cell fates including that of many endodermal endocrine cells. For example, gene targeting experiments in mice have shown that Mash1 is required for endocrine cell differentiation in the lung (Borges et al. 1997), whereas loss of Math1 leads to depletion of the secretory cell lineage in the intestine (Yang et al. 2001). Loss of BETA2/NeuroD results in diminished numbers of pancreatic $\alpha$ - and $\beta$-cells, as well as secretinand cholecystokinin (CCK)-expressing cells of the gut (Naya et al. 1997), whereas deletion of neurogenin 3 results in the absence of all four pancreatic endocrine cell types (Gradwohl et al. 2000). In addition, ablation of the repressor of bHLH gene expression, Hes1, leads to precocious and excessive differentiation of enteroendocrine cells in the gastrointestinal tract, underscoring the importance of the Notch-signaling pathway in the specification of enteroendocrine cells (Jensen et al. 2000). In this study, we have generated mice lacking $n g n 3$ and have analyzed the role of $n g n 3$ during gastric epithelial development. Using this model, we have uncovered an important role for $n g n 3$ in enteroendocrine cell differentiation and the maintenance of gastric epithelial cell identity. 


\section{Results}

\section{Derivation of ngn3-EGFP mice}

To investigate the potential role of the bHLH transcription factor ngn3 during stomach development, we have derived mice homozygous for a null mutation of this gene by homologous recombination in mouse embryonic stem (ES) cells. We constructed a targeting vector that replaces the entire coding region of $n g n 3$ with the enhanced green fluorescent protein (EGFP) gene (Fig. 1A). Of 200 stably transfected ES cell clones obtained after G418 selection, two were homologous recombinants as identified by PCR screening (Fig. 1B; data not shown). Germ-line chimeras and mice heterozygous for the ngn3 mutation were obtained. Heterozygous animals of the original mixed background (129Sv $\times$ C57BL6) were crossed, and the offspring were genotyped by PCR (Fig. 1C). No gross differences were observed between heterozygous and wild-type animals in overall development, growth characteristics, and histology; therefore, mice of both genotypes were used as controls throughout this study.

\section{Ngn3-EGFP marks the enteroendocrine cell lineage of the glandular stomach}

During endocrine lineage development in the pancreas, ngn3 is expressed transiently in endocrine precursor cells, but extinguished in fully differentiated cells /Gradwohl et al. 2000). To investigate the expression domain of ngn3 in the stomach, we made use of our ngn3-EGFP allele to follow the expression of ngn3 by green fluorescence. Ngn3-EGFP was located specifically in the glandular stomach, whereas no expression was detected in the squamous epithelium of the forestomach (Fig. 1F). The image of the ngn3 heterozygous stomach shown in Figure $1 \mathrm{~F}$ was obtained by imaging the entire organ on a confocal fluorescence microscope. Due to the low intensity of the ngn3-EGFP signal, the image was captured from multiple focal planes, thus giving the impression of a high density of enteroendocrine cells in the glandular stomach. To delineate the identity of these EGFP-positive cells, we examined the coexpression of the pan-endocrine marker, Chromogranin A, with EGFP in the stomach of heterozygous mice. In addition to multiple single-label EGFP-positive cells that presumably mark enteroendocrine precursor cells, we also observed numerous EGFP/Chromogranin A double-positive cells. The long half-life of EGFP thus allowed us to trace the fate of the ngn3-EGFP-positive endocrine precursors to their mature descendants. These data suggest that ngn3EGFP marks the enteroendocrine lineage in the stomach (Fig. 1G).

\section{$\mathrm{Ngn}^{-/-}$mice display a disorganized gastric mucosa}

$\mathrm{Ngn} 3^{-/-}$mice derived previously are born alive with reduced size and experience $100 \%$ mortality by postnatal day 3 due to severe diabetes (Gradwohl et al. 2000). We observed similar abnormalities in our $n g n 3^{-/-}$mice (Fig. 1D), including the lack of the four endocrine cell types of the pancreas. However, in addition to this pancreatic phenotype, $n g n 3^{-/-}$mice also have previously undescribed abnormalities in other endodermally derived organs, including smaller stomachs (Fig. 1E). To further analyze the gastric phenotype of $n g n 3^{-/-}$mice, we examined gastric histology in 3-day-old control and ngn3-/mice (Fig. 2A-H). We utilized Alcian blue staining to detect potential transformation of the gastric epithelium to intestinal cell types. Alcian blue stains acidic mucins that are normally found exclusively in the goblet cells of the small intestine and colon. Whereas the gastric mucosa of control mice contained no Alcian blue staining cells (Fig. 2C,E), a significant number of stained cells were found in the $n g n 3^{-1-}$ gastric mucosa (Fig. 2D,F), suggesting regional intestinal metaplasia of the stomach. At higher magnification, we noticed that the Alcian blue positive cells in the $n g n 3^{-/-}$gastric epithelium are elongated, resembling the shape of a goblet cell (Fig. 2F). To assess whether these cells are goblet cells, we examined the ultrastructure of control and $n g n 3^{-/-}$stomachs by electron microscopy. As expected, no goblet cells were present in control stomachs (Fig. 2G), whereas gobletlike cells occurred frequently in the $n g n 3^{-/-}$stomach (Fig. 2H). These goblet cells appear immature, as they exhibit relatively few mucin-containing vesicles.

To support these findings on the molecular level, two intestine-specific markers, Muc2 and iFABP, were analyzed for expression by RT-PCR, RNase protection assay, and immunohistochemistry. Muc2 is normally expressed in goblet cells in the intestine (van Klinken et al. 1999; Longman et al. 2000), and iFABP is restricted to both absorptive enterocytes and goblet cells of the intestine (Sweetser et al. 1988). Muc2 expression was detected in $n g n 3^{-/}$, but not in control stomachs as shown by RT-PCR (Fig. 3A) and RPA (Fig. 3B) analysis. As expected, no iFABP-positive cells were found in the gastric epithelium of controls (Fig. 3C), whereas iFABP expression was induced in the gastric mucosa of $n g n 3^{-/-}$mice (Fig. 3D). Quantification of iFABP-positive cells showed a 13-fold increase in the number of iFABP-expressing cells in the gastric epithelium of $n g n 3^{-/-}$mice compared with littermate controls (Fig. 3E). Taken together, data from histological and molecular analyses implicate ngn3 in the maintenance of the gastric mucosal identity in the developing stomach, as its absence leads to regional intestinal metaplasia of the gastric epithelium.

\section{Proliferation and apoptosis are normal in the gastric epithelium of $\mathrm{Ngn}^{-/-}$mice}

The reduced size and expanded mucosal thickness of $n g n 3^{-/-}$stomachs prompted us to measure rates of proliferation and apoptosis in these mice using $\mathrm{Ki} 67$ and Caspase 3, respectively, as markers (Schluter et al. 1993; Yuan et al. 1993; Stennicke and Salvesen 1997). The pattern and numbers of proliferating cells stained by Ki67 were similar in the gastric mucosa of control and $n g n 3^{-/-}$ mice (Fig. 4A,B). This suggests that the expanded gastric 
Lee et al.

Figure 1. Targeting strategy for ngn3 inactivation. (A) Gene structure of the ngn3 locus (top). Targeting vector used for homologous recombination in ES cells (middle). Gene structure of the targeted allele (bottom). Not all of the restriction enzymes are depicted in the diagram. $(B)$ An ES clone $(8 \mathrm{~F})$ that has undergone homologous recombination was identified using ES screening primers (indicated by red and orange boxes in $A)$. (C) Genotyping by PCR of a litter from an intercross of heterozygous mice. Three sets of genotyping primers (indicated by yellow, blue, and green boxes in $A$ ) were used to generate the wildtype (295 bp) and mutant (188 bp) allele bands. (D) Photograph of 3-day-old wild-type (top) and $n g n 3^{-/-}$mice (bottom) on a mixed $129 \mathrm{~Sv} \times \mathrm{C} 57 \mathrm{BL} 6$ background. $\mathrm{Ngn3}^{-/-}$animals were smaller, dehydrated, and diabetic. (E) Photograph of the stomachs of 3-day-old wild-type (right) and $n g n 3^{-/-}$mice (left). Note the smaller size of the $n g n 3^{-/-}$stomach. $(F)$ Confocal images of EGFP expression in the P3 heterozygous animal. ngn3-EGFP expression is detected only in the glandular stomach. $(G)$ ngn3-EGFP is expressed in the enteroendocrine precursor cells. Confocal image of heterozygous stomach stained using a Cy3-conjugated secondary antibody against Chromogranin A that allows simultaneous detection of Chromogranin A (red) and ngn3 expression (green). Some cells expressed EGFP alone (indicated by o), whereas others were colabeled with both EGFP and Chromogranin A (indicated by arrowheads).
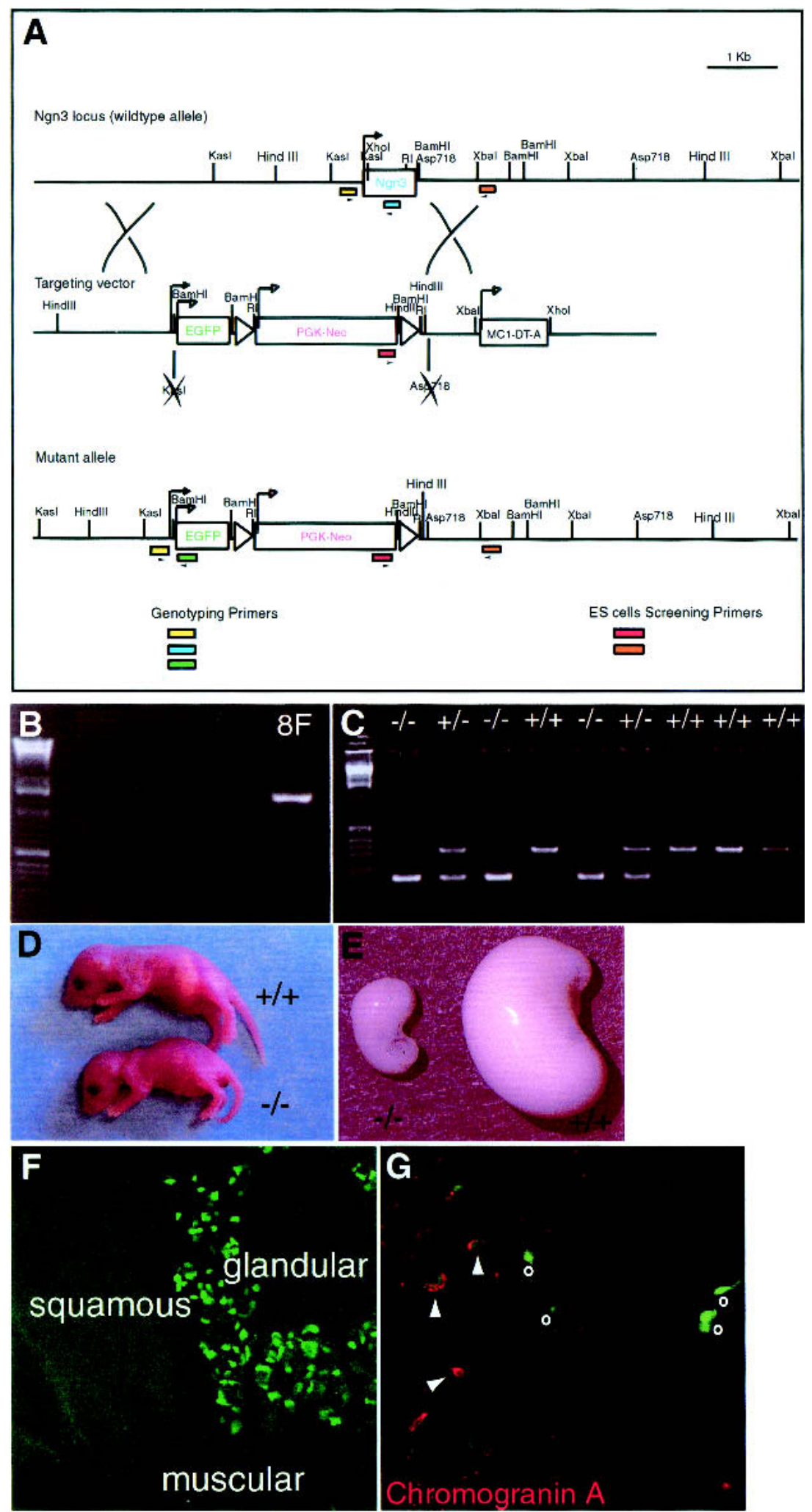

epithelium observed in $n g n 3^{-/-}$mice is not caused by increased proliferation. Next, we examined the possibility of altered programmed cell death in the $n g n 3^{-/-} \mathrm{mu}-$ cosa by caspase 3 staining. As shown in Figure 4, C and
$D$, we did not observe a significant difference in the number of apoptotic cells between control and $n g n 3^{-/-}$ mice. Thus, it appears likely that the disorganization of the $n g n 3^{-/-}$mucosa causes the gastric epithelium to ap- 


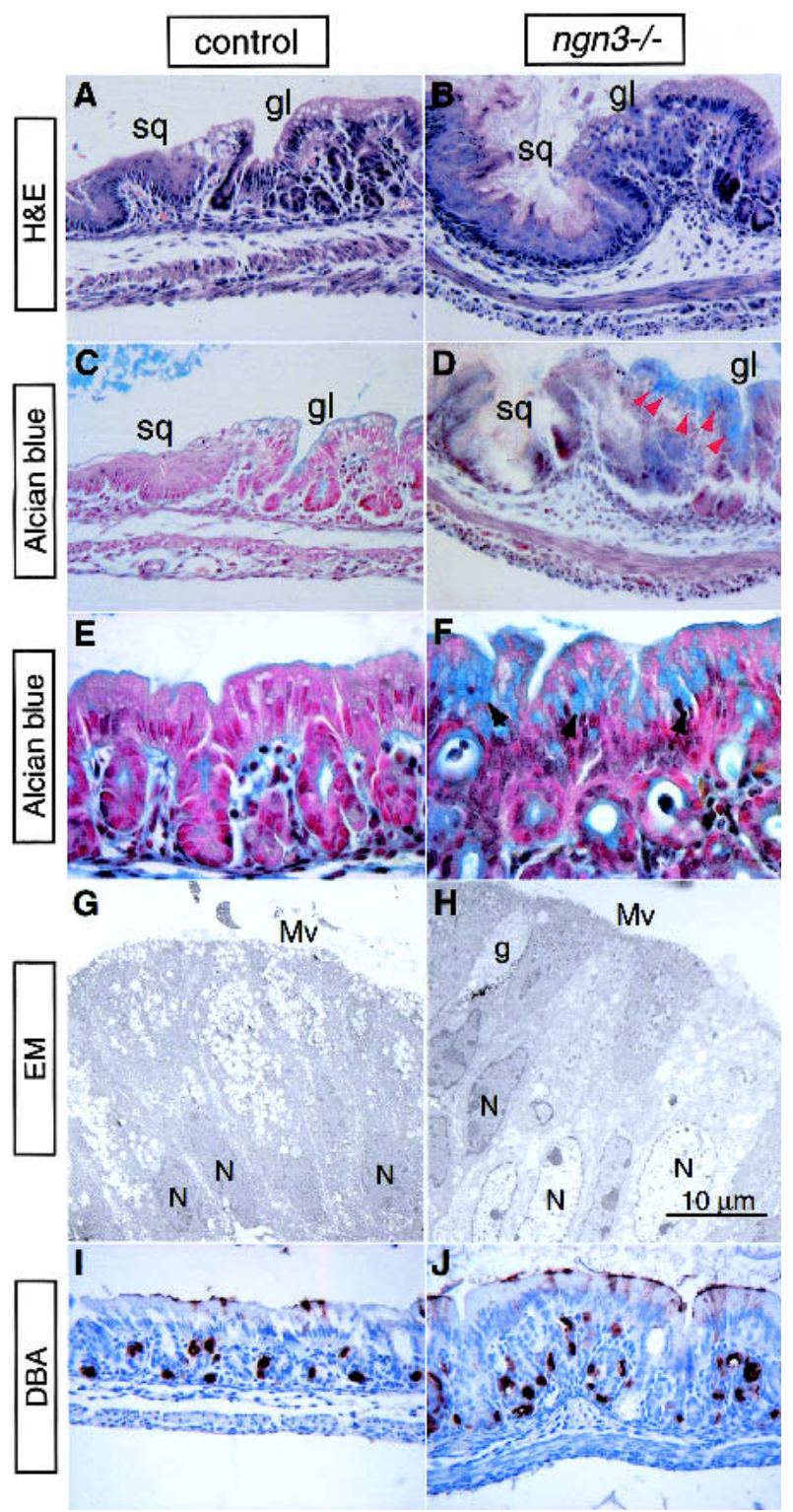

Figure 2. Abnormal stomach development in $n g n 3^{-/-}$mice. Paraffin sections of stomachs obtained from 3-day-old control $(A, C, E, I)$ and $n g n 3^{-/-}$mice $(B, D, F, J)$ were stained with histological and lectin stains. Hematoxylin and eosin staining of control $(A)$ and $n g n 3^{-/-}(B)$ stomachs. Note increased diameter and disorganized appearance of the gastric epithelium in $n g n 3^{-/-}$ mice. $(C, E)$ Alcian blue, which detects acid mucins, normally does not stain the gastric epithelium, but detects ectopic acid mucins in the $n g n 3^{-/-}$mice $(D, F$, indicated by red and black arrowheads). Electron micrographs illustrate the ultrastructural features of the stomach. $(G)$ An image of a control stomach showing normal epithelial morphology, whereas goblet-like cells were present in the $n g n 3^{-/-}$stomach $(H)$. Control and $n g n 3^{-/-}$glandular epithelium were stained with Dolichos biflorus (DBA) lectin, which labels parietal cells, with horseradish peroxidase substrate (brown). The DBA staining shows no difference in the number and distribution of parietal cells between the control $(I)$ and $n g n 3^{-/-}$gastric epithelium $(J)$. Magnification for $A-D$ and $I-I$ is $400 \times, \mathrm{E}-\mathrm{F}$ is $600 \times$, and $G-H$ is $5000 \times$. (sq) Squamous epithelium; (gl) glandular epithelium; (g) goblet cell; $(\mathrm{Mv})$ microvilli; (N) nucleus. pear thicker than that of the control stomach. Finally, it is possible that the smaller size of the stomach in the 3 -day-old $n g n 3^{-/-}$mice is an indirect result of the abnormal metabolic status of these animals, as there was no difference in the fetal development of the organ when stomachs of control and $n g n 3^{-/-}$animals were compared at embryonic day 17.5 (data not shown).

\section{Gastric enteroendocrine differentiation is impaired in $\mathrm{ngn}^{-/-}$mice}

To determine whether enteroendocrine cells are affected in the $n g n 3^{-/-}$stomach, expression of a general enteroendocrine cell marker, Chromogranin A, was examined by immunofluorescence. All major endocrine cell types express Chromogranin A in the stomach (Norlen et al. 2001). As shown in Figure 5, B and C, there were fewer Chromogranin A-positive cells in the $n g n 3^{-/-}$stomach than in the control. To distinguish the subtypes of enteroendocrine cells affected by the lack of ngn3, we utilized markers specific for A-, D-, G-, and EC-cells (Fig. 5A). Whereas cells expressing glucagon, somatostatin, and gastrin were found in the control stomach, none of these peptide hormones was detected in the gastric epithelium of $n g n 3^{-/-}$mice (Fig. 5F-K). In contrast, serotonin-positive cells were still present in the $n g n 3^{-/-}$stomach, but at reduced frequency (Fig. 5D-E; Fig. 6C). The expression of BETA2/NeuroD, a downstream target of ngn3 (Huang et al. 2000), which plays an important role during endodermal endocrine cell differentiation, was absent in the $n g n 3^{-/-}$stomach as assessed by quantitative RT-PCR analysis (data not shown). This suggests that ngn3 regulates the enteroendocrine lineage in the stomach through BETA2/NeuroD, similar to the transcription factor hierarchy that specifies pancreatic endocrine cells (Gradwohl et al. 2000).

\section{Glucagon, somatostatin, and gastrin $m R N A$ s are} absent in the stomach of $\mathrm{ngn}^{-/-}$mice

Although immunofluorescence is useful to investigate enteroendocrine cell differentiation, it is also crucial to determine the expression level of the marker genes quantitatively. Thus, we investigated glucagon, somatostatin, and gastrin mRNA levels in the control and $n g n 3^{-/-}$ stomach by RT-PCR analysis. Consistent with what we have observed in our immunofluorescence studies, glucagon, somatostatin, and gastrin mRNA were completely absent in the $n g n 3^{-/-}$stomach, whereas these transcripts were detected in the control stomach (Fig. 6A). Interestingly, we have found a broad range of gastrin mRNA levels in the control stomachs, which might reflect small differences in the age or nutritional status of these animals.

In addition, we performed microarray expression profiling using various platforms with total RNA extracted from both control and $n g n 3^{-/-}$stomach. As shown in Figure $6 \mathrm{~B}$, the mRNA levels for proglucagon, somatostatin, and gastrin were decreased by 22-, 7-, and 14-fold, 
Lee et al.

Figure 3. Up-regulation of intestine-specific gene expression in the stomach of $n g n 3^{-/-}$mice. Muc2 mRNA-PCR and RNase protection assay (RPA) analysis. (A) RT-PCR analysis of total RNA isolated from whole stomach of control and $n g n 3^{-/-}$mice. Muc2 expression (215 bp) is detected in the $n g n 3^{-1-}$ stomach $(n=2)$, whereas no Muc2 expression is found in the control $(n=2)$. Hypoxanthine phosphoribosyl transferase (HPRT) was used as a loading control (130 bp). (B) RPA analysis of $10 \mu \mathrm{g}$ of total RNA from 3-day-old control $(n=2)$ and $n g n 3^{-/-}$stomach $(n=2)$. Glyceraldehyde phosphate dehydrogenase (GAPDH) served as loading control. Muc2 mRNA was again seen in $n g n 3^{-/-}$stomach. Notably, the $n g n 3^{-/-}$ stomach that showed higher expression of Muc2 by RT-PCR analysis also showed higher expression of Muc2 by RPA (indicated by dot in both $A$ and $B) .(C-D)$ Immunohistochemical detection of intestinal fatty acid-binding protein (iFABP) in $n g n 3^{-/-}$stomach. Paraffin sections from 3 -day-old control and $n g n 3^{-/-}$glandular stomach were stained with an antiserum specific to iFABP (indicated by red arrow-

heads). iFABP is expressed by the misspecified gastric epithelial cells in $n g n 3^{-/-}$mice $(D)$, but was not detected in controls $(C)$. Magnification, 400×. (E) iFABP-positive cells were counted from control $(n=3)$ and $n g n 3^{-/-}$stomachs $(n=3)$. Y-axis represents the iFABP-positive cell counts. $\left({ }^{\star}\right) P<0.02$ by two-tailed Student's $t$-test.

respectively, in $n g n 3^{-/-}$stomachs, consistent with our $\mathrm{RT}-\mathrm{PCR}$ results. In contrast, the intestinal markers, Trefoil factor 3 (TFF3; Mashimo et al. 1995), and iFABP were found to be increased by 18 - and 3 -fold, respectively in the $n g n 3^{-/-}$stomachs, respectively, confirming the presence of regional intestinal metaplasia of the stomach in ngn $3^{-/-}$mice described above. The expression of the $\mathrm{H}^{+/ \mathrm{K}+}$ ATPase, a marker for parietal cells, showed no difference between the control and $n g n 3^{-/-}$stomachs, again confirming our histological findings (see below).

As multiple attempts at establishing an RT-PCR protocol for serotonin were unsuccessful, and as serotonin is
Figure 4. $\mathrm{Ngn}^{-/-}$gastric mucosa does not display abnormal cell proliferation or programmed cell death. Proliferating cells stained by Ki67 are found in the gastric glands (arrowheads), mesenchymal, and muscular layers of control $(A)$ and $n g n 3^{-/-}$stomach $(B)$. There was no significant difference in the number or localization of proliferating cells between the mutant and control groups. Caspase 3 immunostaining (arrowheads) showed no significant changes in numbers of apoptotic cells between control $(C)$ and $n g n 3^{-/-}(D$ stomachs). Magnification, $400 \times$.

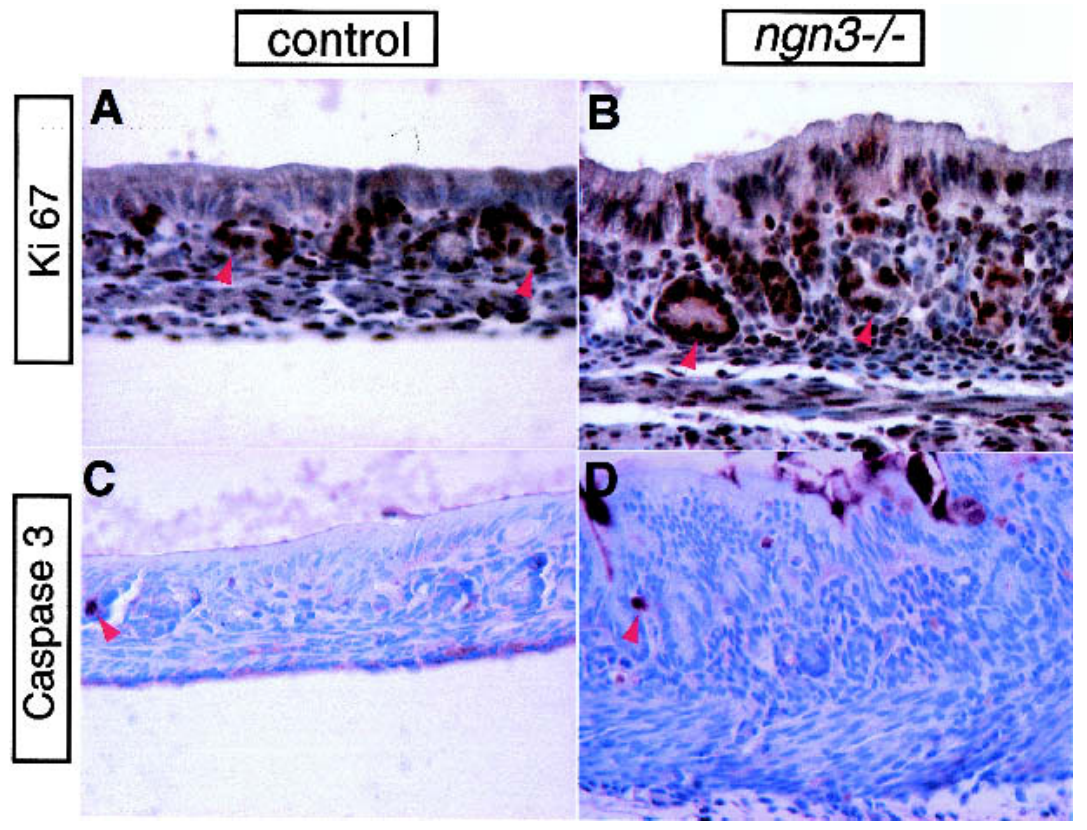


A

A-cells: Glucagon
D-cells: Somatostatin
G-cells: Gastrin
EC-cells: Serotonin
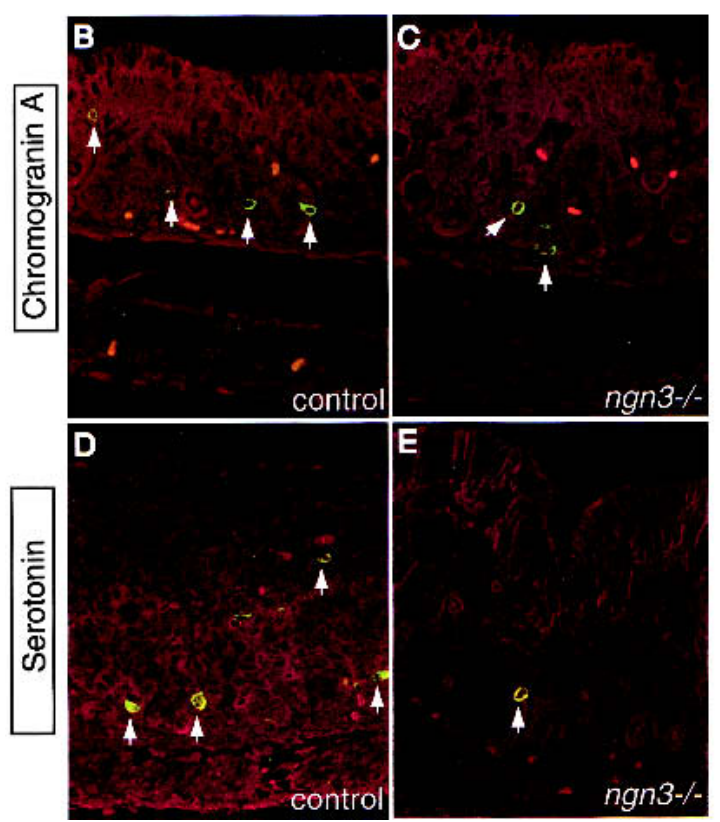
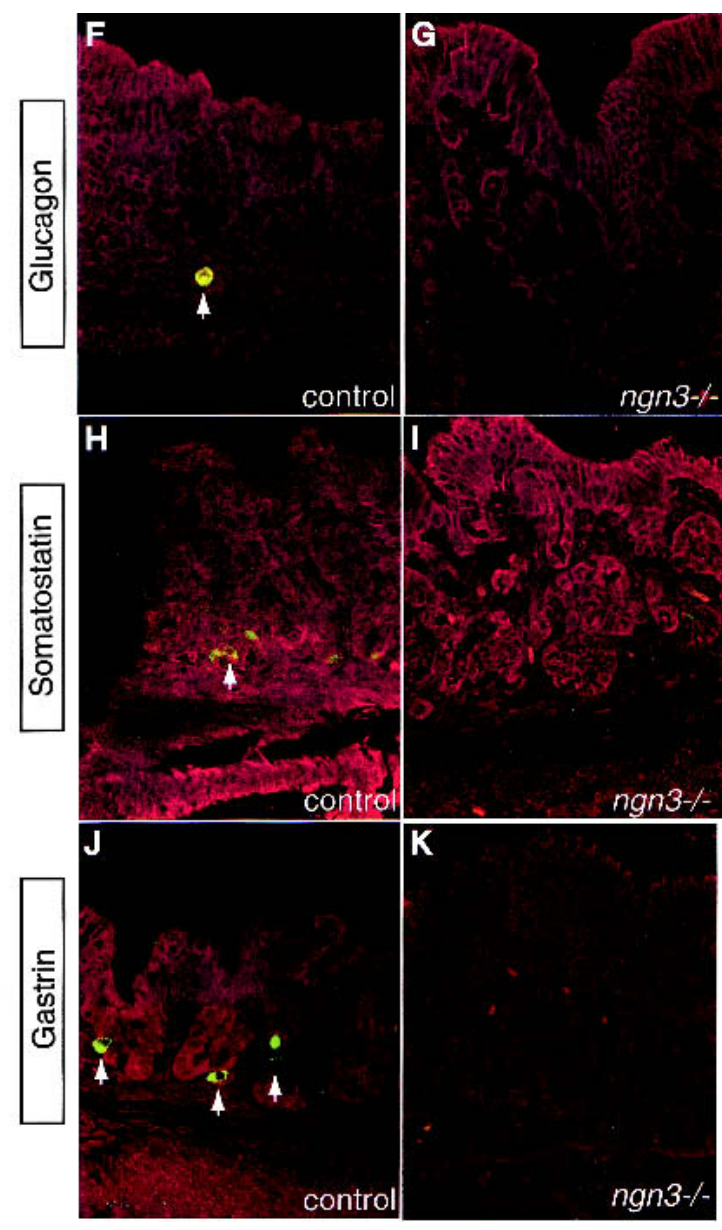

Figure 5. Ngn3 is required for the differentiation of enteroendocrine cells in the gastric epithelium. $(A)$ Classification of enteroendocrine cells by their main secretory products. Immunofluorescence was performed on paraffin sections from 2-3-day-old control $(B, D, F, H, J)$ and $n g n 3^{-/-}(C, E, G, I, K)$ glandular stomach. Immunostained cells are labeled in green for the enteroendocrine cell-specific antigen indicated at left (labeled by white arrows), and images were captured by confocal microscopy. Evan's blue was used as counterstain for the tissues and is visualized in red in all sections (Beaulieu 1997). (B) Chromogranin A, a general endocrine cell maker, labels all subtypes of enteroendocrine cells in the gastric epithelium of control mice. $(C)$ The number of Chromogranin A-expressing cells is reduced in the $n g n 3^{-/-}$gastric epithelium. $(D)$ An enterochromaffin $(\mathrm{EC})$ cell-specific marker, serotonin, is normally expressed by the EC-cells in the control stomach. $(E)$ The number of serotonin-positive cells is reduced in the $n g n 3^{-/-}$stomach. $(F)$ An A-cellspecific enteroendocrine cell marker, glucagon, is normally present in the gastric epithelium of control stomach. $(G)$ No glucagonpositive cells are found in the $n g n 3^{-/-}$gastric epithelium. (H) Somatostatin, a D-cell-specific enteroendocrine cell maker, is found in

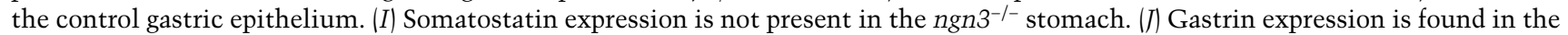
G-cells of control gastric epithelium. $(K)$ No gastrin-positive cells are found in the $n g n 3^{-/-}$gastric epithelium. Magnification, 400×.

not included on the microarrays used for our study, we quantified the level of serotonin expression by counting cells that are immunostained with serotonin antibody from both control and ngn $3^{-/-}$stomachs. We observed an overall sixfold decrease in the numbers of serotoninpositive cells in the $n g n 3^{-/-}$stomachs when compared with controls (Fig. 6C).

\section{Parietal and mucous cells are not affected} in the ngn $3^{-/}$stomach

In addition to enteroendocrine cells, other cell types such as zymogenic cells, mucin-producing pit cells, and parietal cells are also present in the gastric mucosa (Gor- don and Hermiston 1994). As it has been shown that gastrin deficiency leads to a decrease in the number of parietal cells and an increase in mucous neck cell number in gastrin-deficient mice (Koh et al. 1997), we sought to determine whether these lineages were also affected by the loss of gastrin expression observed in the stomach of ngn3-deficient mice (Fig. 5K). For this purpose, we utilized lectin staining, which is a sensitive tool for defining the differentiation program of gut epithelial cell lineages. Immunohistochemistry with DBA and AAA, which label parietal and mucous cells, respectively (Falk et al. 1994), revealed no differences between the control and $n g n 3^{-/-}$stomachs (Fig. 2I-J; data not shown). These data indicate that the gastric parietal and mucous cell 
lineages are not regulated by ngn3 and are not affected by the lack of gastrin in the stomach. The apparent discrepancy in the observations in gastrin-deficient mice cited above might be explained by the difference in the age of the animals investigated. Due to the early lethality of $n g n 3^{-/-}$mice, we had to limit our analysis to postnatal day 3, whereas the phenotype of gastrin null mice is only apparent in adult mice (7-8 wk old) (Koh et al. 1997).

\section{Discussion}

Models for the role of ngn3 during gastric enteroendocrine cell differentiation

Our analysis in $n g n 3^{-/-}$mice suggests the existence of both ngn3-dependent and independent enteroendocrine cell lineages. We propose two models to illustrate how ngn3 might specify gastric enteroendocrine development (Fig. 7). The first model suggests that ngn3 is needed initially for the proliferation of all endocrine cells, and

A

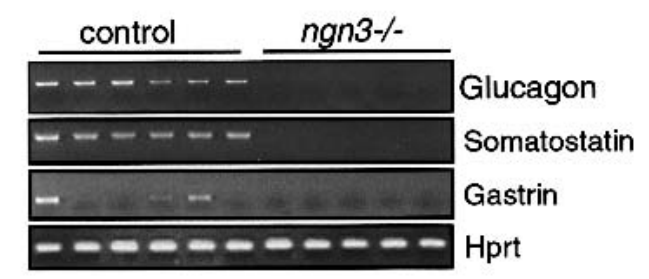

B

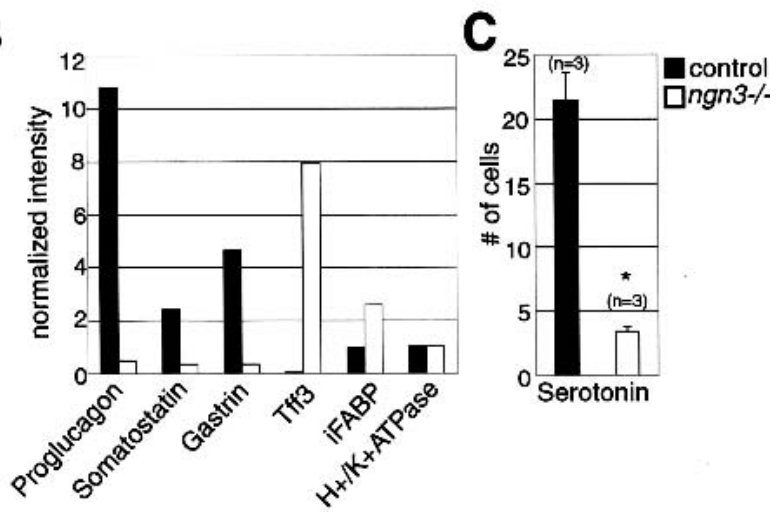

Figure 6. Analysis of mRNA levels of secretory products of enteroendocrine cells and gastrointestinal marker genes. $(A)$ Glucagon, Somatostatin, and Gastrin mRNA are absent in 2-3day-old $n g n 3^{-/-}$stomachs. RT-PCR analysis was performed using the primers indicated and the products separated on $1.5 \%$ ethidium bromide-stained agarose gels. Hprt was used as an internal control. $n=6$ for controls and $n=5$ for $n g n 3^{-/-}$stomachs. (B) Summary of genes with altered expression levels identified by microarray analysis. Y-axis shows the normalized intensity levels and $\mathrm{X}$-axis shows the various genes examined. $n=2$ for controls and $n=3$ for $n g n 3^{-/-}$stomachs. $(C)$ Quantification of serotonin-positive cells. Ten sections from each stomach were counted for both control and $n g n 3^{-/-}$animals. $n=3$ for both control (black bar) and ngn3 $3^{-/-}$stomachs (white bar). Y-axis represents the serotonin-positive cell counts. Serotonin-positive cells were decreased sixfold in the $n g n 3^{-/-}$stomachs. $\left(^{*}\right)$ $P<0.02$ by two-tailed Student's $t$-test.
A

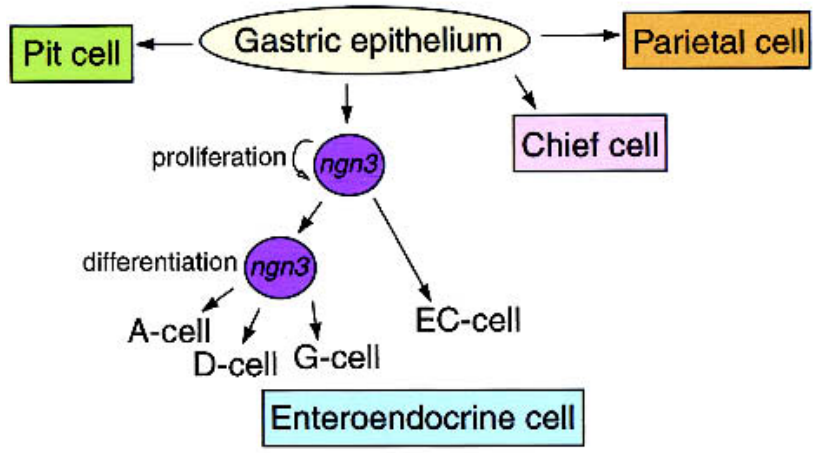

B

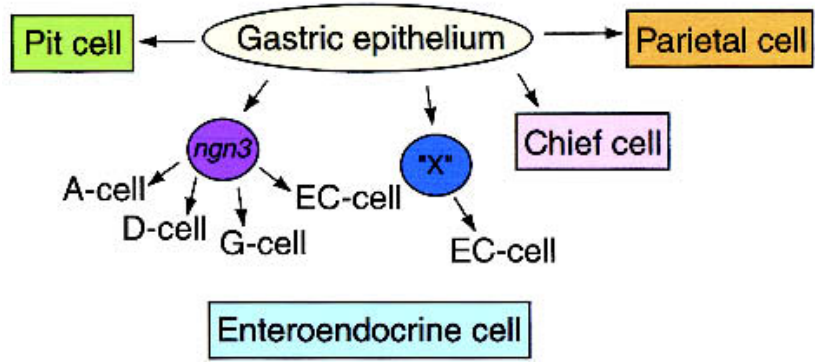

Figure 7. Two models for the proposed role of ngn3 during enteroendocrine cell differentiation in the gastric epithelium. (A) Ngn3 is needed for the proliferation of all enteroendocrine cells, but only required for the differentiation of $\mathrm{A}_{-}, \mathrm{D}-$-, and G-cells. EC-cells can differentiate in an ngn3-independent pathway, but their number is reduced in $n g n 3^{-/-}$; mice as the total pool of enteroendocrine precursor cells is reduced. $(B)$ ngn3 is absolutely required for the differentiation of A-, D-, and G-cells. However, differentiation of the EC-cells can occur from either the ngn3 lineage or another pathway regulated by an unidentified factor $\mathrm{X}$.

subsequently required for the terminal differentiation of A-, D-, and G-cells, but not EC-cells (Fig. 7A). Thus, ngn3 deficiency leads to a smaller pool of enteroendocrine precursors from which EC-cells can differentiate, resulting in the observed reduction in the frequency of this cell type. The second model suggests that ngn3 is absolutely required for the specification of A-, D-, and G-cells, but not EC-cells, because the specification of EC-cells can also be orchestrated by factor X (Fig. 7B). Factor X could be regulated by effectors in the Notch-signaling pathway or by factors in other signaling pathways. Other neurogenin family members such as ngn1 and ngn2 are potential candidates for factor $\mathrm{X}$ that might also be involved in governing enteroendocrine cell specification. In conclusion, we have shown that ngn3 is essential for the specification of enteroendocrine cells in the stomach and for the maintenance of gastric epithelial cell identity.

\section{Materials and methods}

Derivation of the ngn3-EGFP allele

Primers specific to the mouse ngn3 gene were used to screen a 129 SvEv mouse BAC (ㅁacterial artificial chromosome) library 
(Research Genetics). Three BACs containing the ngn3 gene were identified and an 8-kb XbaI fragment of the final ngn3 BAC was subcloned into pBluescript (Stratagene) (ngn3xlx8.0) and used for the construction of the targeting vector. Sequencing confirmed that the entire 642-bp ngn3-coding region was contained in $n g n 3 \times 1 \times 8.0$. Furthermore, $n g n 3 \times 1 \times 8.0$ also contains a $6.4-\mathrm{kb}$ $5^{\prime}$ flanking sequence and 948 bp of 3'UTR. The ngn3-coding region was replaced by the EGFP cDNA and a loxP-pgk-neomycin-loxP resistance cassette. The negative selectable marker Diphtheria Toxin A was cloned outside of the 3' homology of ngn3 to enhance the targeting frequency in ES cells. The targeting scheme is detailed in Figure 1A. The targeting vector was linearized with XhoI and $20 \mu \mathrm{g}$ of DNA was electroporated into $10^{7}$ TL1 embryonic stem cells (Labosky et al. 1997). Stably transfected cells were isolated after selection in $350 \mu \mathrm{g} / \mathrm{mL}$ G418 (GIBCO), and 200 clones were screened for homologous recombinants by PCR using the following primers: ES cell screening primer 1 , 5'-ATAGCGTTGGCTACCCGTGAT-3'; ES cell screening primer 2, 5'-AGTCTCCCCTTGCTCCTCT CC-3'.

PCR reactions were carried out $195^{\circ} \mathrm{C}$ for $5 \mathrm{~min}, 32$ cycles of $95^{\circ} \mathrm{C}$ for $45 \mathrm{sec}, 60^{\circ} \mathrm{C}$ for $45 \mathrm{sec}, 72^{\circ} \mathrm{C}$ for $2.5 \mathrm{~min}$, and $72^{\circ} \mathrm{C}$ for $5 \mathrm{~min}$ ) in a buffer containing $1.5 \mathrm{mM} \mathrm{MgCl}_{2}$. The homologously recombined clones produced a band of $1.5 \mathrm{~kb}$. ES cells from the correctly targeted clones were injected into blastocysts derived from C57BL/6 mice. Blastocysts were transferred to pseudopregnant females and chimeric offspring were identified by the presence of agouti hair. Chimeric males were mated to C57BL/6 females to obtain ES-derived offspring that were analyzed by PCR of tail DNA to identify the heterozygous $\left(\right.$ ngn $\left.^{-/-}\right)$mice. Embryos and mice were also genotyped by PCR using genotyping primers as follows: ngn3-1, 5'-ATACTCTGGTCCCCC GTG-3'; ngn3-2, 5'-TGTTTGCTGAGTGCCAACTC-3'; and EGFP, $5^{\prime}$-GAACTTGTGGCCGTTTACGT-3'. PCR reactions were as follows: $95^{\circ} \mathrm{C}$ for $5 \mathrm{~min}, 32$ cycles of $95^{\circ} \mathrm{C}$ for $45 \mathrm{sec}$, $60^{\circ} \mathrm{C}$ for $45 \mathrm{sec}, 72^{\circ} \mathrm{C}$ for $90 \mathrm{sec}$, and $72^{\circ} \mathrm{C}$ for $5 \mathrm{~min}$, in a buffer containing $1.5 \mathrm{mM} \mathrm{MgCl}_{2}$.

\section{Histology}

Tissues were fixed in $4 \%$ paraformaldehyde overnight at $4^{\circ} \mathrm{C}$, embedded in paraffin, cut to $6-\mu \mathrm{m}$ sections, and applied to Probe-on Plus slides (Fisher Scientific). For Alcian blue staining, tissues were deparaffinized in xylene, rehydrated, and placed in $3 \%$ acetic acid for $3 \mathrm{~min}$ and then incubated in $1 \%$ Alcian blue in $3 \%$ acetic acid $(\mathrm{pH} 2.5)$ for $30 \mathrm{~min}$ and washed in water. The slides were incubated in $0.1 \%$ nuclear fast red for $5 \mathrm{~min}$ as a counterstain, washed in water, dehydrated, and mounted with Cytoseal. For hematoxylin and eosin staining, tissues were incubated after rehydration in hematoxylin for $2.5 \mathrm{~min}$, rinsed in water, dipped quickly in $0.5 \%$ acid alcohol, and washed in water. Tissues were then immersed in $0.2 \% \mathrm{NaHCO}_{3}$, rinsed in water, dipped in eosin for $15 \mathrm{sec}$ and briefly rinsed in water before dehydration and mounting.

\section{Electron microscopy}

Tissues were fixed overnight in $2 \%$ glutaraldehyde in $0.1 \mathrm{M}$ sodium cacodylate $(\mathrm{pH} 7.4)$ at $4^{\circ} \mathrm{C}$. Sections were prepared following the standard protocol (Smith et al. 1985). Briefly, tissues were rinsed with $0.1 \mathrm{M}$ Sodium cacodylate, post fixed with $2 \%$ osmium tetroxide in $0.1 \mathrm{M}$ sodium cacodylate and washed at $4{ }^{\circ} \mathrm{C}$. Tissues were stained with $2 \%$ aqueous uranyl acetate, dehydrated in graded alcohol, and embedded in Embed 812 resin (Electron Microscopy Sciences). Sections $7 \times 10^{-8} \mathrm{~m}$ thick were cut using a Leica Ultracut microtome and mounted on 200 mesh thin bar copper grids, stained in $7 \%$ aqueous uranyl acetate, and counterstained in bismuth subnitrite. Digital images were collected on a JEOL JEM 1010 equipped with a Hamamatsu CCD camera and AMT 12-HR imaging software.

\section{RNA analysis}

Total RNA from postnatal stomach was isolated after homogenization and processed using the Totally RNA extraction kit (Ambion). RNase protection analysis was carried out using 10 $\mu \mathrm{g}$ of total RNA and the RPA II kit (Ambion) following the manufacturer's protocol. The probes used were Muc2 (Silberg et al. 2001) and GAPDH (Ambion). RT-PCR analysis was performed as described previously (Wilson and Melton 1994; Duncan et al. 1997). To determine conditions for quantitative analysis, cDNA samples were diluted serially, and each primer pair was tested for exponential amplification by modifying PCR cycle number and quantifying the signal using PhosphorImager (Molecular Dynamics) analysis. PCR conditions were as follows: one cycle of $94^{\circ} \mathrm{C}, 3 \mathrm{~min} ; 26$ cycles of $94^{\circ} \mathrm{C}, 45 \mathrm{sec} ; 60^{\circ} \mathrm{C}$, $45 \mathrm{sec} ; 72^{\circ} \mathrm{C}$, $90 \mathrm{sec}$; one cycle of $72^{\circ} \mathrm{C}, 5 \mathrm{~min}$ in a buffer containing $1.5 \mathrm{mM} \mathrm{MgCl}_{2}$. The following forward and reverse primers were used for specific amplification (size in basepairs):Muc2 (215 bp), 5'-CATTTCTTGGGGCAGAGTGAG-3' 5'-GAAT GTGAGAGGCTGCTGACC-3'; Hprt (130 bp), 5'-GGCCATC TGCCTAGTAAAGCT-3' 5'-GCTGGCCTATAGGCTCATAGT3'; Proglucagon (330 bp), 5'-GCACATTCACCAGCGACTACA-3' 5'-CTGGTGGCAAGATTGTCCAGA-3'; Somatostatin (444 bp), 5' GCTGAAGAAGACGCTACCGAA-3' 5'-TGCAGGGTCAAGTT GAGCATC-3'; Gastrin (165 bp), 5'-GACCAATGAGGACCTG GAACA-3' 5'-AAAGTCCATCCATCCGTAGGC-3'.

\section{Immunofluorescence and immunohistochemistry}

For immunofluorescence, tissues were fixed, sectioned, and processed as described above. Slides used for Chromogranin A were subjected to microwave antigen retrieval by boiling for $6 \mathrm{~min}$ in a 10-mM citric acid buffer ( $\mathrm{pH}$ 6.0) and allowed to cool for 10 min at room temperature. All slides were washed in PBS, then blocked with protein blocking reagent (Immunotech) for $20 \mathrm{~min}$ at room temperature. The primary antibodies were diluted in PBS containing $0.1 \%$ BSA and $0.2 \%$ Triton X-100 (PBT) unless noted otherwise, and incubated with the sections overnight at $4^{\circ} \mathrm{C}$. Slides were washed in PBS, then incubated with the appropriate secondary antibodies diluted in PBT for $2 \mathrm{~h}$ at room temperature. Slides were washed in PBS. To counterstain the tissues, slides were dipped in $0.01 \%$ Evan's Blue solution for 20 $\mathrm{sec}$, rinsed in PBS, mounted, and examined using confocal microscopy (Leica). The following antibodies were used at the indicated dilutions for immunofluorescence: rabbit anti-Somatostatin (1:50 in Antibody Diluent Solution; Zymed), rabbit anti-Serotonin (1:50 in Antibody Diluent; Zymed), rabbit anti-Glucagon (Zymed), rabbit anti-Chromogranin A (1:3000; Diasorin), rabbit anti-GASP \{Gastrin\} (1:100; BMB), and FITCconjugated donkey anti-rabbit IgG (1:50; Jackson).

For immunohistochemistry, tissues were fixed and processed as described above, and quenched in $2.25 \%$ hydrogen peroxide at room temperature for $20 \mathrm{~min}$. Slides were blocked with Avidin D blocking reagent (Vector) and Biotin blocking reagent (Vector) for $15 \mathrm{~min}$ at room temperature with a quick rinse of PBS in between. All slides were blocked with protein-blocking reagent (Immunotech) for $20 \mathrm{~min}$ at room temperature. The primary antibodies were diluted in PBT and incubated overnight at $4^{\circ} \mathrm{C}$. Slides were washed in PBS and incubated with goat antirabbit (1:200; Vector Laboratories) for $30 \mathrm{~min}$ at $37^{\circ} \mathrm{C}$. Slides 
were rinsed with PBS and incubated with HRP-conjugated $\mathrm{ABC}$ reagent (Vector Elite kit) for $30 \mathrm{~min}$ at $37^{\circ} \mathrm{C}$. Slides were washed and colors were developed using a DAB substrate kit (Vector Laboratories). Slides for Ki67 immunohistochemistry were microwaved for antigen retrieval (see above). The following antibodies were used at the indicated dilutions for immunohistochemistry: rabbit anti-iFABP (1:2500; gift from J. Gordon, Washington University, St. Louis, MO), rabbit anti-human/mouse caspase 3 (activated) (1:750; R\&D Systems), rabbit anti-Ki67 (1: 5000; Novacastra), biotinylated-anti-rabbit IgG (1:200; Vector), and biotinylated-DBA lectin (1:20; EY Laboratories). Ki67 and Caspase 3-labeled nuclei were counted manually in a blinded fashion and care was taken only to evaluate gastric mucosa.

\section{Whole-mount immunostaining}

Milk was removed from the stomach and the tissue fixed in $4 \%$ PFA at room temperature for $30 \mathrm{~min}$. Tissues were washed in PBS $/ 0.1 \%$ TritonX (PT) for $30 \mathrm{~min}$ at room temperature, then blocked in $\mathrm{PT} / 5 \% \mathrm{BSA}$ at $4^{\circ} \mathrm{C}$ overnight. Rabbit anti-Chromogranin A (Diasorin) was added at 1:500 and incubated overnight at $4{ }^{\circ} \mathrm{C}$. Tissues were washed in PT/1\%BSA for $1.5 \mathrm{~h}$ and Goat anti-Rabbit-Cy3 was added at 1:200 in PT/5\%BSA for $1.5 \mathrm{~h}$. Tissues were washed in PBS and mounted in PBS/50\% glycerol for confocal microscopy (Pepling and Spradling 1998).

\section{Microarray analysis}

RNA samples were extracted as described above. cDNA was reverse transcribed and fluorescently labeled from $2 \mu \mathrm{g}$ of total RNA using Cy3 dendrimers (Genisphere) from control $(n=2)$ and mutant $(n=3)$ stomachs. Common controls were pooled from the controls and mutants and labeled with Cy5 dendrimers. These probes were hybridized to the PancChip2 (Scearce et al. 2002) plus 6912 mouse 70-mer oligonucleotides (Operon) at $45^{\circ} \mathrm{C}$ according to the Genisphere protocol. A Genepix Scanner was used to scan the slides and the signals were quantified using the Genepix software (Axon). Concurrently, $10 \mu \mathrm{g}$ of total RNA from control $(n=2)$ and mutant $(n=3)$ stomach were used to screen the Affymetrix MG_U74A version 1 chip. Data were acquired and analyzed according the Affymetrix protocol. Global normalization was used to obtain the normalized intensity levels.

\section{Acknowledgments}

We thank Drs. L.E. Greenbaum, D.G. Silberg, D. Stoffers, J.P. Katz, and F. Boudreau for insightful discussions and critical reading of the manuscript. We gratefully acknowledge the assistance of Dr. G. Swain, Sara McNally, and the members of the Morphology Core at the University of Pennsylvania, Drs. D. Baldwin and J. Wang in the Penn Microarray Facility, and Dr. Shah and the members of the Biomedical Imaging Core Laboratory. We thank Dr. Brian Calvi for the help with confocal microscopy, Kathleen O'Shea for the care of mouse colony, Dr. Jonathan P. Katz for the Muc2 primers, Bree Goldstein for technical assistance, and Dr. Marie Scearce for help with microarray analysis. Our studies were facilitated by the University of Pennsylvania Diabetes Center (P30-DK19525) and the Penn Center for Molecular Studies in Digestive and Liver Disease (P30DK50306). This work was supported by the NIDDK (RO1 DK55342 and RO1 DK53839). C.S.L. is supported by the NIDDK (NRSA F32 DK61226-01). N.P. is supported by National Science and Engineering Research Council of Canada postdoctoral fellowship (BP-220106-1999).
The publication costs of this article were defrayed in part by payment of page charges. This article must therefore be hereby marked "advertisement" in accordance with 18 USC section 1734 solely to indicate this fact.

\section{References}

Artavanis-Tsakonas, S., Rand, M.D., and Lake, R.J. 1999. Notch signaling: Cell fate control and signal integration in development. Science 284: 770-776.

Beaulieu, J.F. 1997. Extracellular matrix components and integrins in relationship to human intestinal epithelial cell differentiation. Prog. Histochem. Cytochem. 31: 1-78.

Borges, M., Linnoila, R.I., van de Velde, H.J., Chen, H., Nelkin, B.D., Mabry, M., Baylin, S.B., and Ball, D.W. 1997. An achaete-scute homologue essential for neuroendocrine differentiation in the lung. Nature 386: 852-855.

Duncan, S.A., Nagy, A., and Chan, W. 1997. Murine gastrulation requires HNF-4 regulated gene expression in the visceral endoderm: Tetraploid rescue of Hnf-4(-/-) embryos. Development 124: 279-287.

Falk, P., Roth, K.A., and Gordon, J.I. 1994. Lectins are sensitive tools for defining the differentiation programs of mouse gut epithelial cell lineages. Am. J. Physiol. 266: G987-G1003.

Gordon, J.I. and Hermiston, M.L. 1994. Differentiation and selfrenewal in the mouse gastrointestinal epithelium. Curr. Opin. Cell. Biol. 6: 795-803.

Gradwohl, G., Dierich, A., LeMeur, M., and Guillemot, F. 2000. neurogenin 3 is required for the development of the four endocrine cell lineages of the pancreas. Proc. Natl. Acad. Sci. 97: 1607-1611.

Huang, H.P., Liu, M., El-Hodiri, H.M., Chu, K., Jamrich, M., and Tsai, M.J. 2000. Regulation of the pancreatic islet-specific gene BETA2 (neuroD) by neurogenin 3. Mol. Cell. Biol. 20: 3292-3307.

Jensen, J., Pedersen, E.E., Galante, P., Hald, J., Heller, R.S., Ishibashi, M., Kageyama, R., Guillemot, F., Serup, P., and Madsen, O.D. 2000. Control of endodermal endocrine development by Hes-1. Nat. Genet. 24: 36-44.

Koh, T.J., Goldenring, J.R., Ito, S., Mashimo, H., Kopin, A.S., Varro, A., Dockray, G.J., and Wang, T.C. 1997. Gastrin deficiency results in altered gastric differentiation and decreased colonic proliferation in mice. Gastroenterology 113: 10151025.

Labosky, P.A., Winnier, G.E., Jetton, T.L., Hargett, L., Ryan, A.K., Rosenfeld, M.G., Parlow, A.F., and Hogan, B.L. 1997. The winged helix gene, Mf3, is required for normal development of the diencephalon and midbrain, postnatal growth and the milk-ejection reflex. Development 124: 1263-1274.

Longman, R.J., Douthwaite, J., Sylvester, P.A., Poulsom, R. Corfield, A.P., Thomas, M.G., and Wright, N.A. 2000. Coordinated localisation of mucins and trefoil peptides in the ulcer associated cell lineage and the gastrointestinal mucosa. Gut 47: 792-800.

Lorenz, R.G. and Gordon, J.I. 1993. Use of transgenic mice to study regulation of gene expression in the parietal cell lineage of gastric units. J. Biol. Chem. 268: 26559-26570.

Mashimo, H., Podolsky, D.K., and Fishman, M.C. 1995. Structure and expression of murine intestinal trefoil factor: High evolutionary conservation and postnatal expression. Biochem. Biophys. Res. Commun. 210: 31-37.

Naya, F.J., Huang, H.P., Qiu, Y., Mutoh, H., DeMayo, F.J., Leiter, A.B., and Tsai, M.J. 1997. Diabetes, defective pancreatic morphogenesis, and abnormal enteroendocrine differentiation in BETA2/neuroD-deficient mice. Genes \& Dev. 
11: 2323-2334.

Norlen, P., Curry, W.J., Bjorkqvist, M., Maule, A., Cunningham, R.T., Hogg, R.B., Harriott, P., Johnston, C.F., Hutton, J.C., and Hakanson, R. 2001. Cell-specific processing of chromogranin A in endocrine cells of the rat stomach. J. Histochem. Cytochem. 49: 9-18.

Pepling, M.E. and Spradling, A.C. 1998. Female mouse germ cells form synchronously dividing cysts. Development 125: 3323-3328.

Scearce, L.M., Brestelli, J., McWeeney, S.K., Lee, C.S., Mazzarelli, J., Pinney, D.F., Pizarro, A., Stoeckert, C.J., Clifton, S., Permutt, M.A., et al. 2002. Functional genomics of the endocrine pancreas: The pancreas clone set and PancChip, new resources for diabetes research. Diabetes (in press).

Schluter, C., Duchrow, M., Wohlenberg, C., Becker, M.H., Key, G., Flad, H.D., and Gerdes, J. 1993. The cell proliferationassociated antigen of antibody Ki-67: A very large, ubiquitous nuclear protein with numerous repeated elements, representing a new kind of cell cycle-maintaining proteins. $J$. Cell. Biol. 123: 513-522.

Silberg, D.G., Sullivan, J., Kang, E., Swain, G.P., Moffett, J., Sund, N.J., Sackett, S.D., and Kaestner, K.H. 2001. Cdx2 ectopic expression induces gastric intestinal metaplasia in transgenic mice. Gastroenterology 122: 689-696.

Skipper, M. and Lewis, J. 2000. Getting to the guts of enteroendocrine differentiation. Nat.Genet. 24: 3-4.

Smith, R.M., Cobb, M.H., Rosen, O.M., and Jarett, L. 1985. Ultrastructural analysis of the organization and distribution of insulin receptors on the surface of 3T3-L1 adipocytes: Rapid microaggregation and migration of occupied receptors. $J$. Cell. Physiol. 123: 167-179.

Sommer, L., Ma, Q., and Anderson, D.J. 1996. neurogenins, a novel family of atonal-related bHLH transcription factors, are putative mammalian neuronal determination genes that reveal progenitor cell heterogeneity in the developing CNS and PNS. Mol. Cell. Neurosci. 8: 221-241.

Stennicke, H.R. and Salvesen, G.S. 1997. Biochemical characteristics of caspases-3, -6, -7, and -8. J. Biol. Chem. 272: 25719-25723.

Sweetser, D.A., Hauft, S.M., Hoppe, P.C., Birkenmeier, E.H., and Gordon, J.I. 1988. Transgenic mice containing intestinal fatty acid-binding protein-human growth hormone fusion genes exhibit correct regional and cell-specific expression of the reporter gene in their small intestine. Proc. Natl. Acad. Sci. 85: 9611-9615.

van Klinken, B.J., Einerhand, A.W., Duits, L.A., Makkink, M.K., Tytgat, K.M., Renes, I.B., Verburg, M., Buller, H.A., and Dekker, J. 1999. Gastrointestinal expression and partial cDNA cloning of murine Muc2. Am. J. Physiol. 276: G115-G124.

Wilson, P.A. and Melton, D.A. 1994. Mesodermal patterning by an inducer gradient depends on secondary cell-cell communication. Curr. Biol. 4: 676-686.

Yang, Q., Bermingham, N.A., Finegold, M.J., and Zoghbi, H.Y. 2001. Requirement of math1 for secretory cell lineage commitment in the mouse intestine. Science 294: 2155-2158.

Yuan, J., Shaham, S., Ledoux, S., Ellis H.M., and Horvitz, H.R. 1993. The C. elegans cell death gene ced-3 encodes a protein similar to mammalian interleukin-1 $\beta$-converting enzyme. Cell 75: 641-652. 


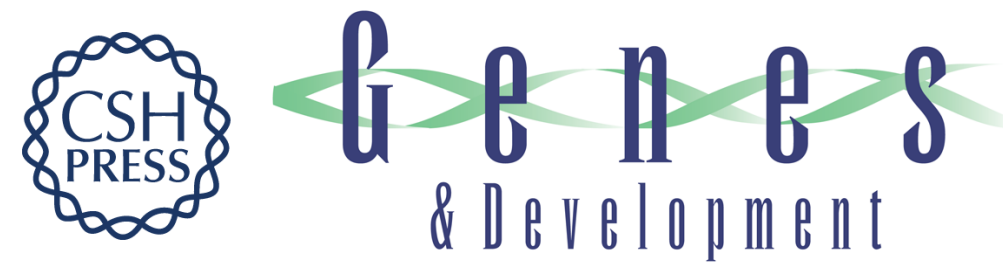

\section{Neurogenin 3 is essential for the proper specification of gastric enteroendocrine cells and the maintenance of gastric epithelial cell identity}

Catherine S. Lee, Nathalie Perreault, John E. Brestelli, et al.

Genes Dev. 2002, 16:

Access the most recent version at doi:10.1101/gad.985002

References This article cites 28 articles, 13 of which can be accessed free at:

http://genesdev.cshlp.org/content/16/12/1488.full.html\#ref-list-1

License

Email Alerting Receive free email alerts when new articles cite this article - sign up in the box at the top

Service right corner of the article or click here.

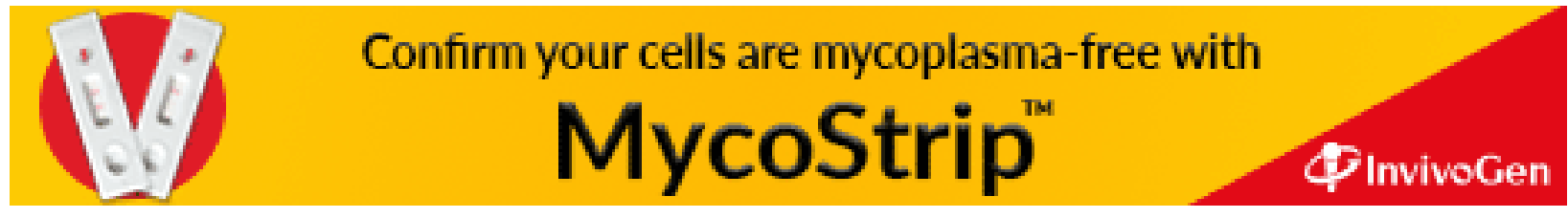

